\title{
Desarrollos del derecho contractual europeo y tradición jurídica*
}

\section{Aldo Petrucci ${ }^{* *}$}

RESUMEN: La presente contribución tiende a una doble finalidad: de una parte, quiere ofrecer una panorámica sobre las nuevas evoluciones del derecho contractual europeo ocurridas en los últimos años y los posibles escenarios futuros, y de otra, concentra su atención sobre las relaciones entre algunas soluciones normativas incluidas en los proyectos que en materia de unificación se han hecho y la larga tradición jurídica europea que se remonta al derecho romano.

Palabras clave: Derecho contractual europeo, Normativa común de compraventa, CESL, tradición jurídica europea.

\section{New Trends of European Contract Law and European Legal Tradition}

Aвstract: This paper has two main purposes: on the one hand, it seeks to offer a general view on new trends in European contract law occurring in recent years and possible future scenarios. On the other hand, it focuses on relations between some legal solutions included in the unification projects that have been conducted and the long European legal tradition dating back to Roman law.

\footnotetext{
* Trad. del italiano, Natalia Rueda.

Fecha de recepción: 24 de marzo de 20I6. Fecha de aceptación: I 8 de abril de 2016.

Para citar el artículo: A. Petrucci, "Desarrollos del derecho contractual europeo y tradición jurídica", Revista de Derecho Privado, Universidad Externado de Colombia, n. ${ }^{\circ}$ 30, enero-junio de 2016, 85-105. DOI: http://dx.doi.org/IO.I860I/oI 234366.n30.04

* Profesor de Derecho Romano y Fundamentos de Derecho Europeo, Università di Pisa, Pisa, Italia. Doctor en Derecho Romano por la Università degli studi di Roma 'La Sapienza', Roma, Italia. Contacto: aldo.petrucci@unipi.it
} 
Keywords: European Contract Law, Common European Sales Law, cess, European Legal Tradition.

Sumario: i. La Propuesta de Reglamento europeo sobre Normativa común de compraventa (CESL Draft): el camino hacia su redacción. 2. Objetivos, ámbito de aplicación y contenido de la Propuesta. 3. La Normativa común de compraventa europea (CESL) en la perspectiva de un mercado único digital europeo (European Digital Single Market): 4. La disciplina contractual en la Normativa común de compraventa y la tradición jurídica europea. a) Algunas observaciones generales. 5. (sigue): b) Algunos ejemplos específicos en las partes II, III y IV.

\section{La Propuesta de Reglamento europeo sobre Normativa común de compraventa (CESL Draft)}

Como se sabe, el momento preliminar a la redacción de un proyecto de Normativa común europea de compraventa fue la publicación del Draft Common Frame of Reference of the European Private Law (en adelante DCFR) en 2009, que representa el esfuerzo más importante que se haya hecho hasta hoy para acercar y armonizar algunos aspectos del derecho privado patrimonial de los Estados miembros de la Unión Europea. Sus objetivos habrían sido hacer aún más coherentes las disposiciones del acquis communautaire (valga decir, de la legislación comunitaria europea ya vigente en materia de derecho privado) en el derecho contractual y promover su aplicación uniforme para facilitar las transacciones transfronterizas y sugerir a los legisladores nacionales un conjunto de reglasmodelo, que habrían podido favorecer la formación de un derecho contractual general y uniforme, en el caso de que hubiera sido adoptado de manera voluntaria por los países miembros de la Unión Europea.

Para la realización del DCFR, la Comisión Europea decidió financiar una investigación trienal, confiada a una Red de investigadores (DCFR-Network) conformada por dos grupos ya existentes: el Grupo de estudio sobre un Código Civil europeo (Study Group on a European Civil Code) y el Grupo de estudio sobre el derecho privado vigente de la Unión Europea (Research Group on Existing EC Private Law); sus tareas y encuentros se desarrollaron entre los años 2004 y 2007 e involucraron no solo investigadores y académicos, sino también expertos y representantes de asociaciones y grupos interesados de los países miembros de la Unión y de otros países europeos como Suiza y Noruega ${ }^{\mathrm{I}}$.

I von Bar, V. C. y Clive, E., Principles, Definitions and Model Rules of European Private Law. Draft Common Frame of Reference, Full Edition, München, 2009, 4 ss.; en italiano cfr. Alpa, G.; Iudica, G.; Perfetti U. y Zatti, P., Il Draft Common Frame of Reference del diritto privato europeo, Padova, 2009; Petrucci, A., "Il Progetto di 'Quadro comune di riferimento (DCFr)", en Luchetti, G. y Petrucci, A., Fondamenti romanistici del diritto europeo. Le obbligazioni e i contratti dalle radici romane al Draft Common Frame of Reference, Bologna, 20 Io, 9 ss. 
El DCFR está dividido en tres partes: a) diez libros de Reglas-Modelo; b) una parte separada de Principios, y c) un anexo relativo a las Definiciones. En relación con el contenido de cada sección, se puede remitir a las indicaciones de los mismos autores en la Introducción ${ }^{2}$.

En la parte de los Principios se delinean cuatro principios informadores (Underlying principles), consistentes en la libertad, seguridad, justicia y eficiencia; las Reglas-Modelo están contenidas en I.023 artículos distribuidos en diez libros y resultan privadas de fuerza normativa, configurándose como reglas de soft law, igual que aquellas de los Principios del Derecho Europeo de los Contratos (PECL, Principles of European Contract Law) escritas por la Comisión

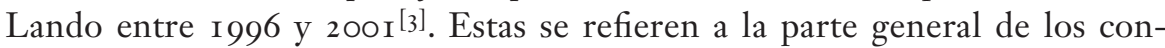
tratos, las obligaciones y los correlativos derechos de crédito, algunos tipos contractuales específicos (compraventa, arrendamiento de bienes, servicios, mandato, franquicia, etc.) así como la gestión de negocios ajenos, la responsabilidad extracontractual por daños a terceros, el enriquecimiento sin justa causa, la adquisición y pérdida de la propiedad sobre bienes muebles, las garantías reales sobre muebles y los trusts. Las Definiciones sirven como sugerencias para favorecer el desarrollo de un lenguaje jurídico y una terminología uniformes a nivel europeo.

Como se ve, aunque el DCFr excluya del proprio ámbito de aplicación las materias de derecho privado enunciadas en el artículo I.-I:IOI (2 ${ }^{4}$, va mucho más allá de los objetivos reservados a un Marco Común de Referencia (CFr, Common Frame of Reference) de la Comisión Europea, porque la adición de partes relativas a obligaciones no contractuales (gestión de negocios ajenos, enriquecimiento injusto y resarcimiento de los daños por responsabilidad extracontractual), a la adquisición y pérdida de la propiedad de bienes muebles, a las garantías reales sobre los mismos y a los trusts, demuestra la independencia del trabajo académico de las limitaciones propias de las decisiones políticas ${ }^{5}$.

Las fuertes críticas en contra del DCFR por parte de muchos estudiosos y representantes de grupos profesionales, debido a sus elecciones sistemáticas y

2 von Bar y Clive, Principles, Definitions and Model Rules of European Private Law, cit., Introduction, I 2 Ss.

3 Para una traducción italiana de los pecl y un comentario de los mismos cfr. Castronovo, C., I principi di diritto contrattuale europeo I y II Parte, Milano, 200 I; III Parte, Milano, 2005.

4 Status y capacidad jurídica de las personas físicas; testamento y sucesiones; relaciones de familia, incluido el matrimonio; letras de cambio, cheques, pagarés y otros instrumentos negociables; relaciones de trabajo; propiedad inmobiliaria y garantías inmobiliarias, derecho societario y relativo a asociaciones con o sin personalidad; materias relacionadas principalmente con el procedimiento o la ejecución.

5 Cfr. von Bar y Clive, Principles, Definitions and Model Rules of European Private Law. Draft Common Frame of Reference (DCFR), Full Edition Introduction, cit., 3. 
metodológicas ${ }^{6}$, y una actitud más cautelosa de las propias instituciones europeas (casi un 'paso atrás') no impidieron, sin embargo, a la Comisión Europea emprender dos importantes iniciativas durante la primera mitad de 2010 . La primera fue la conformación, con decisión del 26 de abril, de un Grupo de expertos (independientes, y en un número no superior a veinte) con la tarea de ayudar a la propia Comisión a preparar un Marco Común de Referencia (CFR) en el ámbito del derecho contractual europeo, seleccionando los aspectos más relevantes del DCFR y mejorándolos, a la luz del acquis y de posteriores estudios. La segunda iniciativa fue la publicación de un Libro Verde el I de julio, sobre las posibles opciones para adoptar un derecho contractual europeo para consumidores, sociedades comerciales y profesionales, consultando también, a ese efecto, a personas del común, organizaciones y órganos de los Estados miembros, con el objetivo de proceder con el instrumento jurídico más idóneo: un reglamento vinculante de manera inmediata o una directiva o recomendación que, en todo caso, habría exigido la mediación de los legisladores nacionales.

El resultado final fue la redacción de un Estudio de factibilidad (Study of feasibility) y la presentación de una Propuesta de Reglamento n. ${ }^{\circ}$ 201 I/O284 del I I de octubre de 20 I I, que comprendía el proyecto de Normativa común de compraventa europea (CESL Draft (сом(20 I I) 635 final). Pasamos ahora a analizar brevemente sus objetivos, ámbito de aplicación y contenido.

\section{Objetivos, ámbito de aplicación y contenido de la Propuesta}

Las autoridades europeas son conscientes de que aún subsisten importantes obstáculos a las actividades económicas transfronterizas que impiden al mercado interno desarrollar plenamente su potencial para el crecimiento y el empleo. Uno de los más importantes fue el elevado costo de las transacciones contractuales, con clara desventaja para los consumidores y profesionales. Menor comercio transfronterizo se traduce en menor competencia y menos importaciones?

Así, el objetivo principal de la propuesta de Normativa común de compraventa europea fue el de reducir de manera significativa los obstáculos y costos, por medio de un conjunto de reglas uniformes en materia de derecho contractual, que prescindieran del lugar de residencia de las partes. A ellas se daría la posibilidad de decidir que sus contratos se gobernaran por la Normativa común de compraventa, caracterizada por un significado e interpretación uni-

6 Comenzando por la Interim Outline Edition of DCFR del 2008: v. Zimmermann, R. et al., "Der Gemeinsame Referenzrahmen für das Europäische Privatrecht. Wertungsfragen und Kodifikationsprobleme", fZ, 63, 2008, 529 ss. y Alpa, G. y Conte, G., "Riflessioni sul progetto di Common Frame of Reference e sulla revisione dell'Acquis communautaire", Riv. dir. civ., 54, 2008, I4I ss.

7 Véase el Considerando n. ${ }^{\circ} 4$ de la Propuesta. 
forme en todos los Estados miembros. De este modo se habría armonizado su regulación en materia de contratos, sin modificar el derecho nacional existente, sino incluyendo un segundo régimen contractual idéntico para toda la Unión. Sin embargo, esto último se habría aplicado para los contratos transfronterizos sólo de manera voluntaria, a partir de un acuerdo expreso de las partes ${ }^{8}$.

La Normativa común de compraventa europea (CESL) prevé tres tipos: contratos de compraventa, contratos de suministro de contenidos digitales y contratos relativos a los servicios ofrecidos por el vendedor, en estrecha y directa relación con los bienes vendidos o el contenido digital suministrado.

Los contratos de compraventa se refieren a aquellos que involucran bienes muebles, incluida su manufactura y producción; de hecho es el tipo contractual más importante para el desarrollo portencial del comercio transfronterizo y, en particular, del comercio electrónico (e-commerce). Los contratos de suministro de contenidos digitales aluden a su transferencia para el archivo y gestión de documentos, tratamiento de datos y acceso a los mismos, y para uso repetido, como la posibilidad de descarga de música o películas; la difusión de este segundo tipo de contratos está aumentando rápidamente y presenta un potencial considerable para un futuro crecimiento. Los contratos relativos a los servicios son aquellos estrecha y directamente relacionados con las mercancías vendidas o con el contenido digital suministrado, que el vendedor ofrece normalmente junto con la compraventa o el suministro, por ejemplo la instalación, manutención y/o reparación de los bienes o del contenido digital.

La Propuesta de Reglamento no contemplaba la posibilidad de incluir reglas relativas a contratos mixtos diferentes de estos tres tipos. La Normativa común de compraventa europea se habría podido aplicar sólo si el vendedor de los bienes o el proveedor de contenidos digitales hubiera sido un empresario y la contraparte un consumidor o una pequeña o mediana empresa, identificada según los criterios de la Recomendación de la Comisión europea 2003/36I del 6 de mayo de 2003 .

Toda vez que la Normativa común de compraventa europea se dirigía a regular los contratos transfronterizos, justamente para superar las discrepancias entre ordenamientos nacionales y las correlativas dificultades y costos adicionales, se previó valorar la naturaleza transfronteriza de un contrato sobre la base de la residencia habitual con referencia al empresario, y de la dirección general o de entrega de las mercancías o de la factura para el consumidor, que habrían debido estar en dos Estados distintos. Adicionalmente, se dejó abierta la posibilidad de aplicar la Normativa común de compraventa europea también a contratos transfronterizos celebrados con países ajenos a la Unión Europea para favorecer un incremento del comercio con ellos. 
De hecho, de conformidad con el artículo I3 de la Propuesta de Reglamento, un Estado miembro habría podido decidir extender el régimen de la normativa común también a: a) los contratos en los cuales la residencia habitual del empresario y la dirección general o de entrega de las mercancías o de la factura para el consumidor estuvieran al interior del mismo Estado, y/o b) los contratos en los cuales ambas partes fueran empresarios, ninguno de ellos calificado como pequeña o mediana empresa.

En fin, el contenido de la Normativa común de compraventa europea (CESL) se divide en ocho partes, dos de las cuales (IV y v) se ocupan específicamente de los tipos contractuales ahora vistos y, por tanto, se titulan respectivamente: $O b$ ligaciones y remedios de las partes de un contrato de compraventa (o de suministro de contenidos digitales) y Obligaciones y remedios de las partes de un contrato de servicio asociado. Mientras que las otras seis partes contienen materias relativas a la disciplina general del contrato.

La Parte I (Disposiciones preliminares) contiene los principios generales de libertad de contratación y de buena fe contractual, y define al mismo tiempo nociones clave como la razonabilidad, la forma de los contratos, las cláusulas no negociadas individualmente y el cómputo del tiempo. La Parte II (Carácter vinculante de un contrato) comprende disposiciones sobre: los deberes precontractuales de información; los requisitos para la celebración de un contrato; la posibilidad de anulación por error, dolo, amenaza o explotación injusta; y, el derecho de los consumidores de desistir de los contratos celebrados a distancia o negociados por fuera de los establecimientos comerciales. La Parte III (Valoración del contenido de un contrato) comprende normas relativas a la interpretación de los contratos, a su contenido y efectos, así como a las cláusulas abusivas. La Parte vi (Resarcimiento del daño e intereses) recoge reglas generales suplementarias sobre el resarcimiento de los daños y sobre los intereses de mora; mientras la Parte VII (Restituciones) concierne a aquello que se debe restituir en caso de nulidad o ejecución de un contrato, y la Parte viII (Prescripción) regula los efectos del paso del tiempo sobre el ejercicio de los derechos derivados de un contrato.

Sin embargo, las partes iv y v, en relación con las obligaciones del vendedor y del adquirente, también ofrecen disposiciones básicas sobre el cumplimiento de los contratos, como aquellas relativas al cumplimiento por un tercero y las formas de cumplimiento.

Si se compara la Normativa común europea en materia de compraventa con el Proyecto de Marco Común de Referencia (DCFR) es posible constatar, como afirma el Considerando n. ${ }^{\circ} 27$ de la Propuesta de Reglamento, que se excluyeron del primero aspectos relevantes del derecho contractual y de las obligaciones, como por ejemplo, la invalidez de un contrato por falta de capacidad, ilicitud o contrariedad a las buenas costumbres; la determinación del idioma del contrato; la no discriminación; la representación; la pluralidad de deudores y acreedores; la cesión del contrato; la compensación y la confusión. 


\section{La Normativa común de compraventa europea (CESL) en la perspectiva de un mercado único digital europeo (European Digital Single Market)}

El Proyecto de Normativa común de compraventa europea ha suscitado muchas reservas y críticas de amplios sectores del mundo académico y profesional que señalan, en particular, la contradicción entre la decisión de incluir este régimen jurídico en un reglamento -aplicable de manera inmediata en cada Estado de la Unión- y el carácter voluntario de su aplicación para los contratantes, la ausencia de comentarios sobre el contenido de los artículos, la omisión de materias importantes del derecho contractual, el afán excesivo en la tarea de redacción, con consiguientes imprecisiones terminológicas y conceptuales, la extrema dificultad para los consumidores de comprender el significado de varias normas relativas a sus derechos 9 .

Durante el año 20r3 el contenido de la Propuesta se discutió ampliamente por las autoridades de la Unión Europea: de una parte, la Comisión Judicial y el Comité de Asuntos Jurídicos estaban firmemente decididos a presentarlo al Parlamento Europeo tal como se redactó, sin cambios; de otra, la Comisión de Mercado Interior y Protección del Consumidor consideraba preferible limitarlo sólo a los contratos de compraventa entre empresarios y consumidores, suprimiendo todas las partes relativas al régimen general del contrato ${ }^{\mathrm{IO}}$.

Pareció prevalecer la primera posición, y el 26 de febrero de 2014 el Parlamento Europeo, en una primera lectura, adoptó una Resolución ( $\mathrm{P}_{7}$-TA (2014) or 59) que acogió en todas sus partes la Propuesta de Reglamento, aunque con significativas modificaciones, entre las cuales la más importante es aquella que limita el ámbito a las "transacciones transfronterizas para la compraventa de mercancías, para el suministro de contenidos digitales y para los servicios asociados celebrados a distancia y, en particular, en línea, cuando los contratantes hubieran acordado sobre ello" (Enmienda I al Considerando n. ${ }^{\circ}$ 8). Sin embargo, en la misma resolución, la Comisión Europea fue invitada a proponer de nuevo el tema al Parlamento, precisando si pretendía modificar sustancialmente la Propuesta o sustituirla con una nueva, y su Presidente fue encargado de informar dicha decisión al Consejo de los Estados miembros y a los Parlamentos nacionales.

En diciembre de 2014, la Comisión en su Plan de trabajo 2015 (Work Program 2015 (Сом(20I4) 9io final) tomó la decisión de modificar la Propuesta “con

9 Ver, p. ej., Zimmermann, R. et al., "Der Vorschlag für eine Verordnung über ein Gemeinsames Europäisches Kaufrecht. Defizite der neuesten Textstufe des Europäischen Vertragsrechts”, $7 Z$, 67, 2012,269 ss.

Io Sobre dichas fases cfr. Castronovo, C., "Armonizzazione senza codificazione. La penetrazione asfittica del diritto europeo", en Navarretta, E. (ed.), La metafora delle fonti e il diritto privato europeo. Giornate di studio per Umberto Breccia, Torino, 2015 , I I 3 ss. 
el fin de reactivar plenamente el potencial del comercio electrónico (e-commerce) en un mercado único digital (Digital Single Market)", y desde entonces trabaja en esa dirección ${ }^{\mathrm{II}}$.

En consecuencia, el 6 de mayo de 2015 se emitió una comunicación sobre la Estrategia de un mercado digital único (Digital Single Market Strategy ( Directrices de política dadas a conocer el i 5 de julio de 20 I 4 por Jean-Claude Junker a la Comisión presidida por él, se prometieron ambiciosas iniciativas legislativas favorables a un mercado digital único, modernizando y simplificando las normas de tutela de los consumidores en la contratación digital y en línea ${ }^{\mathrm{I} 2}$. En esta estrategia, el derecho contractual también está llamado a jugar un rol importante con el fin de promover un mejor acceso de los consumidores y profesionales a bienes y servicios en línea en toda Europa. Ello explica por qué la Comisión publicó en julio de 20 I 5 un documento inicial sobre la verificación del impacto (Inception Impact Assessment), relativo a una propuesta sobre las normas contractuales para las adquisiciones en línea, de contenido digital y de bienes muebles, del cual se colige su punto de vista al respecto ${ }^{13}$.

Aún no es claro si la Normativa europea sobre compraventa en línea será incluida en un reglamento o una directiva, puesto que se consideran las dos opciones. Por el contrario, ya se anunció precisamente su contenido y ámbito de aplicación, incluyendo un conjunto de reglas obligatorias para los contratos, internos o transfronterizos, que tengan por objeto las adquisiciones de bienes y el suministro de contenido digital.

\section{La disciplina contractual en la Normativa común de compraventa y la tradición jurídica europea: a) Algunas observaciones generales}

Con independencia de la aplicación de la Normativa común de compraventa europea al futuro mercado digital único, ciertamente puede resultar útil comparar algunas tendencias del derecho contractual contenidas en ella, con la tradición jurídica europea, para comprobar si es posible encontrar algunas raíces o vínculos que hayan sido considerados de manera más o menos consciente.

I I Cfr. Mańko, R., Contract Law and the Single Digital Market. Towards a New EU Online Consumers Sales Law?, ERPs Briefing, PE 568.322, septiembre de 2015, 3 s., I 8 ss., disponible también en: http://epthinktank.eu/201 5/10/o8/european-contract-law-and-the-digital-single-marketpolicy-hub/

I Juncker, J.-C., A New Start for Europe: My Agenda for Fobs, Growth Fairness and Democratic Change: Political Guidelines for the Next European Commission, I 5 July 20I4, disponible en: http:// ec.europa.eu/archives/juncker-commission/

I3 Cfr. http://ec.europa.eu/smart-regulation/roadmaps/docs/20I5_just_oo8_contract_rules_for_ digital_purchases-en.pdf 
A diferencia del Proyecto de Marco Común de Referencia (DCfr), en la Normativa común de compraventa europea (CESL) no se dispone de comentarios o notas sobre todo el conjunto de normas y sobre los distintos artículos, que faciliten la comprensión de las decisiones tomadas y su motivación en relación con los ordenamientos nacionales y la tradición jurídica europea. En todo caso, si se tiene en cuenta que el Proyecto de Marco Común de Referencia representó la 'caja de herramientas' de la cual se extrajeron muchas disposiciones de la Normativa común de compraventa, y que algunos miembros participaron en los dos grupos de redacción, me parece extremadamente útil comenzar por las declaraciones explícitas de los editores en su Introducción al primer "Proyecto" en 2009.

Ellos admiten que su trabajo pretende promover el conocimiento del derecho privado europeo como ordenamiento jurídico superior respecto de los ordenamientos nacionales, así como promover la formación jurídica sobre el mismo. En particular, la función consiste en demostrar las similitudes con el derecho privado de cada país, ofreciendo así un estímulo para el desarrollo de un proceso de unificación, y poniendo de relieve que cada ordenamiento nacional se debe considerar como una manifestación regional de una herencia común y dominante ${ }^{\mathrm{I}}$.

Esta función aparece también en las notas y comentarios de todos los artículos de las reglas-modelo del DCFR, donde se ve que solo en pocos casos los ordenamientos jurídicos europeos dan respuestas diversas a problemáticas comunes.

De este modo, los propios editores se muestran conscientes de la existencia de una 'berencia común europea', evidente en varios ordenamientos, y con simples variaciones regionales, haciendo más fácil la tarea de redactar normas y principios uniformes en materia de contratos, obligaciones y propiedad de bienes muebles. Si bien no se precisa cuál es esta herencia común, no existe ninguna duda de que se identifica con el conjunto de principios y reglas provenientes del derecho romano, de la tradición jurídica medieval y del derecho canónico, que constituyeron por siglos el ius commune europaeum.

Naturalmente, este es el mismo contexto de historia jurídica en el que aparece la CESL. Si se analiza desde este punto de vista, es posible destacar, con referencia a la Parte I, la decisión de los redactores de incluir dos principios generales y vinculantes del derecho contractual al comienzo de las Disposiciones preliminares. Esta elección parece seguir el Proyecto de Marco Común de Referencia, donde en una sección autónoma se incluyen los cuatro principios fundamentales de libertad, justicia, eficiencia y seguridad, incluso antes que las reglas-modelo, así como la praxis del legislador europeo, que tiene el hábito de incluir las definiciones conceptuales básicas antes de los artículos.

I4 Así von Bar y Clive, Principles, Definitions and Model Rules of European Private Law. Draft Common Frame of Reference (DCFR), Full Edition, Introduction, cit., 4. 
Pero también es cierto que no se puede ignorar la conexión con la elección sistemática hecha en el Corpus iuris civilis de Justiniano y su fuerte influencia en la tradición jurídica posterior. Sin entrar en detalles, se puede observar que: a) el primer título tanto de las Institutiones (I. I, I) como del Digesto (D. I, I), ambos sobre la justicia y sobre el derecho (de iustitia et iure), ofrecen algunos principios básicos y fundamentales para toda la codificación; b) el concepto de principio (principium) destacado en D. I, 2, I (Gayo I ad legem duodecim tabularum) significa, ora el elemento inicial necesario para comprender el desarrollo histórico de todas las normas, ora su fundamento; c) al final del Digesto se pueden encontrar como Apéndices los títulos 50, i6 (Sobre el significado de las palabras, de verborum significatione), y 50, I 7 (Sobre las diversas reglas del derecho antiguo, de diversis regulis iuris antiqui), que comprenden definiciones de términos y conceptos recurrentes, así como una lista de disposiciones generales aplicables a todo el Corpus iuris ${ }^{15}$. Por consiguiente, muchos códigos civiles europeos, como el francés, el austriaco, el español, el suizo y el italiano, tienen títulos preliminares con las disposiciones sobre el ámbito de aplicación de la ley en general, pero también con algunos principios básicos al respecto.

Con relación a la libertad de contratación y a la buena fe contractual se puede destacar lo que sigue.

El artículo I de la Normativa común europea en materia de compraventa define la libertad de contratación de este modo: “I. Las partes serán libres de celebrar un contrato así como de determinar su contenido, sin perjuicio de las normas imperativas aplicables. Las partes podrán excluir la aplicación de cualesquiera de las disposiciones de la Normativa común de compraventa europea, así como introducir excepciones o modificar sus efectos, salvo que en dichas disposiciones se disponga lo contrario" ${ }^{\circ}$. Este es un principio común del derecho contractual, bien conocido en todos los ordenamientos jurídicos contemporáneos de Europa. Resultaría demasiado extenso, y tal vez no tan interesante para nuestra perspectiva, volver sobre la evolución histórica desde el derecho romano al iusnaturalismo, pasando por el derecho común y la lex mercatoria, hasta su completa recepción en los ordenamientos del siglo xix, en relación con las restricciones de respeto de las normas imperativas, del orden público y de las buenas costumbres ${ }^{17}$. La Normativa común de compraventa europea lo confirma.

I 5 Ver al respecto Luchetti y Petrucci, Fondamenti romanistici del diritto europeo, cit., 2 I ss.

I6 * Nota de trad.: Las citas textuales de los artículos de la Normativa se toman de la versión oficial en español del Parlamento y la Comisión Europea, disponible en: http://eur-lex.europa.eu/ legal-content/EN/TXT/?uri=celex:520 I I PCo635

i 7 Para una síntesis véase Cassarino, A., "Autonomia delle parti”, en Luchetti y Petrucci, Fondamenti romanistici del diritto europeo, cit., 93 ss. 
Parece más útil un breve análisis histórico de la buena fe contractual, mencionada de manera explícita en el artículo 2: "I. Cada parte tendrá el deber de actuar conforme a las exigencias de la buena fe contractual. 2. El incumplimiento de este deber podrá impedir a la parte incumplidora el ejercicio o la invocación de los derechos, remedios o medios de defensa que, en otro caso, tendría, o podrá hacerla responsable por cualquier pérdida causada a la otra parte. 3. Las partes no podrán excluir la aplicación del presente artículo, ni introducir excepciones o modificar sus efectos", y de manera implícita en el artículo 3 en materia de cooperación: "Las partes estarán obligadas a cooperar entre sí en la medida en que quepa esperar dicha cooperación para el cumplimiento de sus obligaciones contractuales.

Los ordenamientos jurídicos europeos no aplican el principio de la buena fe contractual del mismo modo: en Suiza, Alemania, Austria, Polonia, Holanda e Italia, por ejemplo, se da un uso más amplio y multidireccional de este principio, mientras que en Inglaterra, Francia y España su rol es más difuso ${ }^{18}$. El conocimiento de la manera como se empleó en el derecho romano y en la tradición jurídica europea anterior a los códigos civiles nacionales del siglo XIX podría contribuir a entender la potencialidad y las razones por las cuales resulta recogido en los proyectos de armonización y unificación del derecho contractual europeo.

Revisando algunos textos de la jurisprudencia romana, podemos encontrar tres funciones principales de la buena fe contractual (bona fides) ${ }^{19}$ : la primera es aquella de servir como estándar para valorar la conducta de las partes en la ejecución del contrato y en la conservación del vínculo sinalagmático entre sus prestaciones (synallagma) ${ }^{20}$; la segunda es la de reconstruir y realizar en el mejor modo posible el acuerdo entre los contratantes (id quod actum est) ${ }^{2}{ }^{\mathrm{I}}$; la tercera función es la de integrar el contenido del contrato determinado por las partes ${ }^{22}$. Esta comparación con el derecho romano, también recogido por la tradición jurídica sucesiva, es, a mi modo de ver, muy importante para evitar una errada asimilación entre el más amplio concepto de buena fe contractual, al que se refiere la CESL, y su más estrecho concepto comúnmente usado en el comercio internacional.

Cfr. mi breve ensayo Petrucci, A., "Buona fede e correttezza", en Luchetti y Petrucci, Fondamenti romanistici del diritto europeo, cit., 49 ss.

I9 Ver Stolfi, E., 'Bonae fidei interpretatio'. Ricerche sull'interpretazione di buona fede fra esperienza romana e tradizione romanistica, Napoli, 2004, I 73 ss.; CARDILli, R., 'Bona fides' tra storia e sistema, 2. ${ }^{\text {a }}$ ed., Torino, 2010,29 ss.

20 P. ej., D. i 9.r.50 (LABEón, 4 posteriorum a Iavoleno epitomatorum); Institutas de Gayo 4.6I-63; 4. I I9; D. I6.3.3 I (TRIfoniano, 9 disputationum).

2 I D. I 9.2.2 I (Javoleno, I I epistularum); D. I9.I.I I. I (Ulpiano, 32 ad edictum).

22 Instituciones de Gayo 3.I37; D. I9.I.48 (Escévola 2 responsorum). 
Más precisamente, la buena fe contractual en el comercio internacional no se aplica según los estándares normalmente adoptados en los ordenamientos nacionales, sino sobre la base de las condiciones especiales del propio comercio internacional. De hecho, tales estándares se refieren a las prácticas comerciales, que pueden variar de manera considerable de un sector a otro, e incluso al interior de un sector determinado pueden ser más o menos estrictos en función del ambiente socioeconómico en el que actúen las empresas, sus dimensiones y capacidades técnicas, etc. ${ }^{23}$.

En el marco de un concepto más amplio de buena fe y lealtad podemos también incluir, como ya se dijo, el artículo 3 CEsL sobre la cooperación, que representa un corolario de la necesidad de realizar la voluntad de las partes. Esta disposición es muy importante para promover la armonización entre los ordenamientos jurídicos europeos que ya la conocen (incluida o no en el Código Civil) y aquellos que no.

\section{5. (sigue): b) Algunos ejemplos específicos en las partes II, III y IV}

En la Parte in de la Normativa común europea de compraventa, llamada Carácter vinculante de un contrato, podemos destacar el gran número de normas del Capítulo 2 sobre la responsabilidad de los empresarios por violación de los deberes precontractuales de información. Al respecto se cuentan $\mathrm{I} 7$ artículos en relación con la información que un empresario debe entregar durante las negociaciones con un consumidor u otro empresario, los contratos celebrados con medios electrónicos, la exactitud de la información y los remedios en caso de violación. Un régimen sobre deberes precontractuales de información como este resulta en cierto modo sorprendente, si pensamos en la evolución histórica de la categoría de la responsabilidad precontractual.

En el derecho romano, como es sabido, no existía como tal: se pueden encontrar solo algunos ejemplos de comportamiento doloso durante las negociaciones (dolus in contrabendo) ${ }^{24}$; luego se debe esperar hasta Grocio en el siglo XVII y a la teoría de JHERING sobre la culpa in contrahendo en el siglo XIX para disponer de una construcción conceptual de la responsabilidad precontractual como categoría aparte. Como se sabe, Grocio prefirió encuadrarla en el ámbito de la responsabilidad extracontractual y su posición influenció fuertemente el pensamiento jurídico francés, mientras JHering, que la consideró una rama de la responsabilidad contractual, orientó la ciencia jurídica del mundo alemán. La primera regulación explícita de la materia se encuentra en dos artículos del Código Civil italiano vigente de 1942 (arts. I337 y I338), seguido por un artículo

23 Art. I.7 de los Principios Unidroit 20 Io, con el comentario en pp. 20-2 I.

24 Ver, p. ej., D. I8.r.62. I (Modestino, 5 regularum); D. i9. I.I3.5 (Ulpiano, 32 ad edictum); Instituciones de Justiniano $3.23 \cdot 5$. 
del Código Civil portugués (art. 227), y sólo más tarde fue recogida en el nuevo texto del $\S 3$ I I BGB, incisos 2 y 3, modificado por la Ley de Modernización del derecho de las obligaciones de $200 \mathrm{I}^{[25]}$.

La creciente y actual importancia de la responsabilidad precontractual se puede comprender comparando los dos artículos (2:30 I y 2:302) del proyecto de los PECL publicado en 200 I por la Comisión Lando con todo el tercer capítulo del llbro ir del DCFR ( 5 artículos en total) compuesto por cinco secciones, tres de las cuales están dedicadas específicamente a los deberes precontractuales de información entre consumidores y profesionales. Sólo dos artículos del capítulo 2 fueron reservados al ámbito tradicional de la responsabilidad precontractual: el artículo 2:30 I sobre "Negociaciones contrarias a la buena fe" y el artículo 2:302 sobre la "Violación de la confidencialidad", para establecer una clara separación entre áreas de contratación individual y estandarizada ${ }^{26}$.

De conformidad con los objetivos antes mencionados $(\$ 2)$, la Normativa común europea sobre compraventa no hace referencia al deber de buena fe en las negociaciones precontractuales, porque en ella se consideran solo contratos entre empresarios y consumidores o solo entre empresarios.

La segunda parte de la CESL nos ofrece también la oportunidad de hacer algunas consideraciones útiles sobre las normas relativas a los requisitos para la celebración de un contrato y sobre los vicios del consentimiento en su largo camino desde el derecho romano hasta hoy. Primero se analiza el artículo 30 sobre los requisitos, que en el inciso I dice: "El contrato se habrá celebrado si: (a) las partes alcanzan un acuerdo; (b) las partes tienen la intención de que el acuerdo tenga efecto jurídico; y (c) el acuerdo, completado en su caso por reglas de la normativa común de compraventa europea, tiene el contenido y la certeza suficientes como para que se le dote de efecto jurídico".

El contenido de este artículo es sustancialmente el mismo de los correspondientes artículos del DCFr, de los Pecl y de los Principios Unidroit, con el objetivo de simplificar al máximo los requisitos para la celebración de un contrato, que resume en: I) un acuerdo, 2) sus efectos jurídicos, 3) certeza y contenido suficiente para producir tales efectos. Por el contrario, no menciona ni la capacidad de los contratantes (ya por fuera del ámbito de aplicación de la CESL) ni otros requisitos eventualmente exigidos en los ordenamientos nacionales, como la causa, la consideration, la forma o la entrega de una $\operatorname{cosa}^{27}$. Asistimos, de ese

25 Cfr. Petrucci, A., "Responsabilità precontrattuale: trattative e doveri di riservatezza", en Luchetti y Petrucci, Fondamenti romanistici del diritto europeo, cit., i I I ss.

26 Sobre el particular se reenvía a Alpa, G., Presentazione, en Il Draft Common Frame of Reference del diritto privato europeo, Padova, 2009, vir ss., y Lucchini Guastalla, E., "Marketing and Pre-contractual Duties nel 'Draft Common Frame of Reference', ibíd., I 35 ss.

27 Sobre esta elección en el Dcfr cfr. von Bar y Clive, Principles, Definitions and Model Rules of European Private Law. Draft Common Frame of Reference (DCFR). Full Edition, cit., 264 ss. 
modo, a una evidente confirmación de una tendencia expresa en los principales proyectos de unificación y armonización del derecho contractual europeo.

El derecho romano no contaba con una teoría general relativa a todos los requisitos necesarios para la celebración de un contrato, en cuanto estos variaban según el tipo contractual. Un primer intento importante de enumerarlos se debe probablemente a juristas medievales, como BALDo, mientras un desarrollo sistemático posterior en esta dirección se encuentra en la Escuela francesa de derecho natural ${ }^{28}$.

La elección de la Normativa común de compraventa europea nos indica una preferencia por aquellos ordenamientos jurídicos europeos (como el francés, el español y el italiano) donde existe un artículo del código civil con una lista precisa de los requisitos contractuales esenciales ${ }^{29}$, alejándose en cambio de otros ordenamientos del sistema continental (como el suizo, el alemán y el holandés), donde aquellos deben deducirse del régimen general del negocio jurídico o del acto jurídico o del contrato.

Los vicios del consentimiento están regulados en el Capítulo 5 y consisten en el error, el dolo, las amenazas y la explotación injusta. La identificación de los tres primeros vicios en la CESL sigue una larga y probada tradición jurídica basada en el derecho romano y desarrollada por la ciencia jurídica medieval y moderna. Los conceptos de error, dolo y amenazas incluyen, básicamente, elementos comunes y bien conocidos, pero también algo nuevo.

A propósito del error, el artículo 48 señala que una parte puede hacer anular un contrato no sólo por error de hecho, sino también de derecho, en contraste con aquello establecido en la mayoría de los ordenamientos jurídicos europeos, que generalmente admiten solo el primero (p. ej., el art. I429 c.c. italiano). Ahora bien, un contratante puede solicitar la anulación solo si el error: a) existía cuando se celebró el contrato; b) la parte, de no haber existido el error, no lo habría celebrado o lo habría hecho en otras condiciones; y c) la otra parte provocó el error o actuó de modo que el contrato se celebrara bajo error, omitiendo el cumplimiento de los deberes precontractuales de información, o conocía o debía conocer el error y actuó de manera que se celebrara el contrato, no revelando la información exigida por la buena fe o incluso cometiendo el error mismo.

Así, para poder anular un contrato, el error debe: I) existir al momento de celebrar el contrato, 2) influir de manera fundamental en el consentimiento de una parte para celebrarlo, y 3 ) depender de la otra parte o ser común. Esta disciplina sobre el error relevante representa un esfuerzo apreciable por reorganizar y completar aquella contenida en los códigos civiles europeos, que intentaron

28 Me permito remitir a mis observaciones en Petrucci, A., "Requisiti generali per la formazione del contratto", en Luchetti y Petrucci, Fondamenti romanistici del diritto europeo, cit., i 3 o ss.

29 Arts. I IO8 c.c. francés, I 26 I c.c. español y I 325 c.c. italiano. 
resumir los principios derivados de las soluciones de los casos ofrecidas por los juristas romanos y medievales (error in negotio, error in persona, error in corpore, error in substantia, error in qualitate, etc. $)^{30}$ : por ejemplo, tenemos un solo artículo en el Código Civil francés (art. I I Iо), dos parágrafos en el вGв: (\$\$ I I9-I20), dos artículos en el Código Civil polaco (arts. 84-85), cinco artículos en el Código suizo de las Obligaciones (arts. 23-27) y seis artículos en el Código Civil italiano (arts. I428-I433). Además, la disciplina de la CESL podría marcar un hito para resolver la caótica situación jurídica sobre los errores contractuales relevantes existente en los ordenamientos europeos de common law.

En relación con el dolo, según el artículo 49, una parte puede reclamar la anulación del contrato, si la otra la indujo a celebrarlo mediante una representación fraudulenta de la realidad, con palabras o actuaciones, o mediante una no revelación fraudulenta de la información exigida por la buena fe o los deberes precontractuales de información. Luego sigue una descripción de qué es una representación fraudulenta de la realidad y una no revelación fraudulenta de la información requerida, cuyo resultado fue inducir a la contraparte a cometer el error $^{3 \mathrm{I}}$, de conformidad con la visión tradicional del dolo en la celebración de un contrato; se incluye, en fin, una lista de todas las circunstancias que deben tenerse en cuenta para determinar aquello que exige la buena $\mathrm{fe}^{3^{2}}$.

El contenido del artículo 49 CESL básicamente reproduce el texto del artículo II.-7:205 DCFR; de una parte, completa las disposiciones más breves de muchos códigos civiles europeos (como el art. I I I 6 c.c. francés, el \$ I 23 в вв, el art. 28 C. suizo de las Obligaciones, los arts. I439-I440 c.c. italiano); y de otra, simplifica el régimen jurídico del dolo, omitiendo la distinción entre dolus causam dans e dolus incidens. Con ello, la Normativa común de compraventa europea parece preferir la idea unitaria del dolo que encontramos en las fuentes del derecho romano.

En el artículo 50 cEsL las amenazas están definidas como el comportamiento de una parte que indujo a la otra a celebrar el contrato, amenazándola con la causación de un daño injusto, inminente y serio o de un acto ilícito. Tales ele-

30 Cfr. Zimmermann, R., The Law of Obligations, Oxford, I996, 583 ss.; Petrucci, A., Lezioni di diritto privato romano, Torino, 2015, 305 ss.

3 I "Una declaración es dolosa si se hace con el conocimiento o en la creencia de que la declaración es falsa, o temerariamente en cuanto a su condición de verdadera o falsa, y su finalidad es que el destinatario incurra en un error. La ocultación de información es dolosa si se hace con el propósito de inducir a la persona a la que se oculta a que cometa un error".

"Para determinar si, de acuerdo con la buena fe contractual, una parte tenía la obligación de comunicar a la otra una información concreta, deberá atenderse a todas las circunstancias, entre ellas: (a) si la parte tenía conocimientos especializados sobre la materia; (b) el coste que supone para la parte obtener la información pertinente; c) la facilidad con la que la otra parte podría haber obtenido la información por otros medios; (d) la naturaleza de la información; (e) la importancia que aparentemente tenía dicha información para la otra parte; y (f) en los contratos entre comerciantes, las buenas prácticas comerciales en la situación en cuestión”. 
mentos pueden relacionarse con el concepto de metus del derecho romano y de la tradición romanista, y fueron recogidos en algunos códigos civiles europeos (como los arts. I I I 2- I I I 5 c.c. francés, los arts. 29-30 c. suizo de las obligaciones, los arts. I434-I 438 c.c. italiano), mientras otros prefirieron no dar definiciones, como el $\$$ г 23 в вв que exige simplemente una transacción celebrada ilegítimamente mediante violencia. Los redactores del CESL siguieron la regla modelo contenida en el artículo II.-7:206 DCFR, que opta por una solución intermedia.

En cuanto a la explotación injusta, sus raíces se pueden remontar seguramente al derecho romano y a la doctrina de la laesio enormis de la ciencia jurídica medieval, de donde pasó a los ordenamientos jurídicos modernos (como el francés, el alemán, el suizo y el italiano). Tanto el artículo II.-7:207 DCFR como el 5 I CESL regulan la explotación injusta en términos similares y su concepto no es muy distinto del tradicional, porque exige que al momento de la celebración de un contrato: a) una parte sea dependiente de la otra o tenga con ella una relación de confianza o esté en situación de necesidad económica o tenga necesidades urgentes o sea imprevisora, ignorante o inexperta, y b) la otra parte lo supiera o hubiera debido saberlo y, a la luz de las circunstancias y del objetivo del contrato, haya aprovechado esa situación recibiendo un excesivo beneficio o una ventaja injusta. Lo que podemos destacar es la tendencia a revivir este instituto después de su declive en términos prácticos durante el siglo xix y la primera mitad del xx.

También en muchos artículos de la Parte III, titulada "Valoración del contenido de un contrato", emergen vínculos evidentes con el derecho romano y la tradición romanista, como se puede observar en las normas del Capítulo 6 sobre interpretación del contrato y del Capítulo 7 sobre sus contenidos y efectos. Dos ejemplos pueden ser suficientes.

El primero tiene que ver con los artículos $6 \mathrm{Ib}$ y 62 , inciso Ia, relativos a la interpretación a favor de los consumidores y la interpretación en contra del autor de la cláusula contractual. Sus textos son el resultado de una larga evolución histórica, que inició con la propia interpretatio contra stipulantem, extendida luego en el derecho romano a toda cláusula contractual de dudoso significado incluida por una parte (interpretatio contra proferentem) ${ }^{33}$. A lo largo de la ciencia jurídica medieval y moderna de los siglos xvir y xvinI esta regla hermenéutica permeó algunos códigos civiles del siglo xix, entre ellos el Código Civil francés (art. I I 62) y español (art. I 288), mientras otros ordenamientos europeos la acogieron en el marco de la interpretación del contrato según la buena fe (p. ej., el \$ I 57 вGв) ${ }^{34}$.

33 Cfr. D. 2.r4.39 (Papiniano, 5 quaestionum); D. i8.r.2 I (Paulo, 5 ad Sabinum) ; D. 45.I.38.r 8 (Ulpiano, 49 ad Sabinum).

34 Ver al respecto Zimmermann, The Law of Obligations cit., 639 ss.; Petrucci, A., "Interpretazione del contratto: altre regole ermeneutiche", en Luchetti y Petrucci, Fondamenti romanistici del diritto europeo, cit., 348 ss. 
Probablemente es mérito del Código Civil italiano de 1942 haber incluido una norma más específica (el art. I37), que ofrece una interpretación en contra del autor de la cláusula contractual que no haya sido negociada individualmente, cuando haya dudas sobre su significado. Esta norma, con el nombre de contra proferentem-rule, fue añadida en el DCFR y posteriormente desarrollada y completada por la Normativa común de compraventa europea, donde se hace una clara distinción entre contratos celebrados por consumidores y todos los demás contratos en los que una cláusula contractual fue agregada por una parte. Para el primer tipo de contratos el artículo 6r ib afirma: "I. Cuando haya duda sobre el significado de una cláusula contractual en un contrato entre un empresario y un consumidor, deberá prevalecer la interpretación más favorable al consumidor, a menos que la cláusula en cuestión haya sido añadida por el propio consumidor. 2. Las partes no pueden, en perjuicio del consumidor, excluir la aplicación de este artículo, como tampoco derogar o modificar sus efectos" 35 ; para el segundo tipo de contratos el artículo 62, inciso ra, dispone: "no obstante lo dispuesto en el art. 6I $\mathrm{I}$, cuando haya dudas sobre el significado de una cláusula contractual que no se haya negociado individualmente [...] deberá prevalecer una interpretación contra la parte que la hizo incluir".

Mi segundo y último ejemplo hace referencia a la determinación del precio, regulada por los artículos 73,74 y 75 cesL. En el primer artículo el precio a pagar en un contrato, cuando el monto no pueda determinarse de otro modo, es, "salvo disposición en contrario, el que normalmente se hubiera pagado en circunstancias comparables en el momento de la celebración del contrato, y si este no pudiera determinarse, un precio razonable”. Este texto se copió casi en su totalidad de los artículos 55 de la Convención de las Naciones Unidas sobre los contratos de compraventa internacional de mercaderías, 5.I.7 de los Principios UNIDROIT Y II.-9:IO4 DCFR.

De acuerdo con el artículo 74, la determinación unilateral del precio establecida por una parte se admite, pero cuando sea "manifiestamente irrazonable" se aplicará "el precio cobrado normalmente o la cláusula aplicada normalmente en circunstancias comparables en el momento de la celebración del contrato o, si no se dispone de tal precio o cláusula, por otro precio o cláusula razonable". Por su parte, el artículo 75 hace referencia a la determinación del precio o de cualquier otra cláusula contractual por parte de un tercero, examinando dos casos distintos: a) si el tercero no puede o no quiere hacerlo, un juez puede nombrar otro para determinarlo, a menos que ello contradiga las condiciones contractuales; b) si el precio u otra cláusula contractual determinada por un tercero es manifiestamente irrazonable, se sustituirán con el precio normalmente cobrado o la cláusula normalmente usada en circunstancias análogas al momento 
de la celebración del contrato y, en caso de que estos no estén disponibles, un precio o cláusula razonables ${ }^{36}$.

También para la regulación apenas descrita podemos encontrar algunas raíces en el Corpus iuris civilis de Justiniano, donde el precio estaba determinado en el marco del contrato de compraventa con referencia a la decisión de un tercero o a circunstancias externas ${ }^{37}$. Estas fuentes jurídicas romanas influenciaron de manera profunda la ciencia jurídica medieval y moderna, aunque con resultados distintos. Por ejemplo, el Código Civil francés (art. I 592) sólo admitía la determinación por un tercero y fue necesario un largo camino para aceptar la posibilidad de que los contratantes pudieran referirse también a circunstancias objetivas externas. En cambio la ciencia jurídica alemana del siglo xix construyó, basándose en los textos romanos, una teoría muy completa sobre la determinación del objeto de una obligación con referencia a circunstancias externas o a la decisión de un tercero. Esta teoría se incluyó en el Código Civil alemán, cuyo régimen detallado ( $\$ \$ 3$ I 5-3 I 9 ) fue simplificado y usado como base para la posterior regulación del DCFR y de la $\mathrm{CESL}^{3}{ }^{8}$.

Permítase ahora una breve observación final sobre el orden sistemático de las normas sobre contratos de compraventa y suministro de contenidos digitales recogidas en la Parte iv del CESL, donde se exponen las obligaciones del vendedor (Cap. Io) seguidas por los remedios para el comprador (Cap. I I), las obligaciones del comprador (Cap. I 2), seguidas por los remedios para el vendedor (Cap. I3) y, en fin, completa todo el régimen el Capítulo I 4 sobre la transmisión del riesgo.

Desde mi punto de vista, es realmente interesante y, al mismo tiempo, sorprendente que se haya adoptado un método expositivo en el que las obligaciones de una parte se relacionan con los remedios otorgados a la otra en caso de incumplimiento, y que ambas sean equilibradas por la distribución del riesgo por pérdida o daños a las mercancías o al contenido digital objeto del contrato. Como es bien sabido, la correlación entre las obligaciones del deudor y los remedios a favor del acreedor, así como el rol del riesgo y de su transmisión de un contratante al otro son típicos del modo de pensar de la jurisprudencia romana clásica y caracterizan el derecho privado de esa época.

${ }_{3} 6$ "i. Cuando la determinación del precio o de cualquier otra cláusula contractual se deje en manos de un tercero y este no pueda o quiera hacerlo, un órgano jurisdiccional tendrá competencia para designar a otra persona que asuma esta tarea siempre que no contravenga las cláusulas contractuales. 2. Si el precio o cualquier otra cláusula contractual fijada por un tercero resulta manifiestamente irrazonable, ese precio o cláusula se sustituirá por el precio cobrado normalmente o la cláusula aplicada normalmente en circunstancias comparables en el momento de la celebración del contrato o, si no se dispone de tal precio o cláusula, por otro precio o cláusula razonable".

37 Cfr. D. i8.r.35.I (Gayo, io ad edictum provinciale); D. I8.I.7.I-2 (Ulpiano, 28 ad edictum) e Instituciones de Justiniano 3.23.I.

$3^{8}$ V. Petrucci, A., Determinazione del prezzo, en Luchetti y Petrucci, Fondamenti di diritto contrattuale europeo, cit., I22 ss. 
Al final de mis rápidas reflexiones sobre algunas reglas de la Normativa común de compraventa europea en la óptica de la tradición jurídica común, estoy firmemente convencido de la importancia de conocer sus orígenes y raíces, no solo para comprender mejor algunas decisiones 'tradicionales' de los redactores de los proyectos y del mundo académico europeo en su esfuerzo por armonizar y unificar el derecho contractual, sino también para tener una mayor y más profunda conciencia de la ratio de sus nuevas ramas, como los deberes precontractuales de información o las cláusulas abusivas, que entraron definitivamente en nuestra teoría y práctica jurídica actual.

\section{Bibliografía}

Alpa, G., Presentazione, en Il Draft Common Frame of Reference del diritto privato europeo, Padova, 2009, viI ss.

Alpa, G. y Conte, G., "Riflessioni sul progetto di Common Frame of Reference e sulla revisione dell'Acquis communautaire", Riv. dir. civ., 54, 2008, I4I ss.

Alpa, G.; Iudica, G.; Perfetti U. y Zatti, P., Il Draft Common Frame of Reference del diritto privato europeo, Padova, 2009.

Bar, C. von y Clive, E., Principles, Definitions and Model Rules of European Private Law. Draft Common Frame of Reference, Full Edition, München, 2009, 4 ss.

Cardilli, R., 'Bona fides' tra storia e sistema, 2. ' ed., Torino, 20 Io.

Cassarino, A., "Autonomia delle parti”, en Luchetti, G. y Petrucci, A., Fondamenti di diritto contrattuale europeo. Le obbligazioni e $i$ contratti dalle radici romane al Draft Common Frame of Reference, Bologna, 2010, 93 ss.

Castronovo, C., "Armonizzazione senza codificazione. La penetrazione asfittica del diritto europeo", en Navarretta, E. (ed.), La metafora delle fonti e il diritto privato europeo. Giornate di studio per Umberto Breccia, Torino, 20 I 5, I I 3 ss.

Castronovo, C., I principi di diritto contrattuale europeo, i y in Parte, Milano, 200 I; III Parte, Milano, 2005.

Juncker, J.-C., A New Start for Europe: My Agenda for Fobs, Growth Fairness and Democratic Change: Political Guidelines for the Next European Commission, I 5 July 20I4, disponible en: http://ec.europa.eu/archives/juncker-commission/ 
Lucchini Guastalla, E., "Marketing and Pre-contractual Duties nel 'Draft Common Frame of Reference", en $\mathrm{Il}$ Draft Common Frame of Reference del diritto privato europeo, Padova, 2009, I35 ss.

Mańko, R., Contract Law and the Single Digital Market. Towards a New EU Online Consumers Sales Law?, ERPs Briefing, PE 568.32 2, septiembre de 2015, 3 s., I 8 ss., disponible también en: http://epthinktank.eu/20 I 5/Io/o8/europeancontract-law-and-the-digital-single-market-policy-hub/

Petrucci, A., "Buona fede e correttezza", en Luchetti, G. y Petrucci, A., Fondamenti di diritto contrattuale europeo. Le obbligazioni e $i$ contratti dalle radici romane al Draft Common Frame of Reference, Bologna, 2o Io, 49 ss.

Petrucci, A., "Determinazione del prezzo", en Luchetti, G. y Petrucci, A., Fondamenti di diritto contrattuale europeo. Le obbligazioni e $i$ contratti dalle radici romane al Draft Common Frame of Reference, Bologna, 2010, I 22 ss.

Petrucci, A., "Il Progetto di 'Quadro comune di riferimento (DCFr)'”, en Luchetti, G. y Petrucci, A., Fondamenti romanistici del diritto europeo. Le obbligazioni e i contratti dalle radici romane al Draft Common Frame of Reference, Bologna, 2oro, 9 ss.

Petrucci, A., "Interpretazione del contratto: altre regole ermeneutiche", en Luchetti, G. y Petrucci, A., Fondamenti romanistici del diritto europeo. Le obbligazioni e i contratti dalle radici romane al Draft Common Frame of Reference, Bologna, 2010, 348 ss.

Petrucci, A., Lezioni di diritto privato romano, Torino, 2015.

Petrucci, A., "Requisiti generali per la Formazione del contratto", en Luchetti, G. y Petrucci, A., Fondamenti romanistici del diritto europeo. Le obbligazioni e $i$ contratti dalle radici romane al Draft Common Frame of Reference, Bologna, 20 IO, I 30 ss.

Petrucci, A., "Responsabilità precontrattuale: trattative e doveri di riservatezza”, en Luchetti, G. y Petrucci, A., Fondamenti romanistici del diritto europeo. Le obbligazioni e $i$ contratti dalle radici romane al Draft Common Frame of Reference, Bologna, 2oro, i I I ss.

Stolfi, V. E., 'Bonae fidei interpretatio'. Ricerche sull'interpretazione di buona fede fra esperienza romana e tradizione romanistica, Napoli, 2004. 
Zimmermann, R. et al., "Der Gemeinsame Referenzrahmen für das Europäische Privatrecht. Wertungsfragen und Kodifikationsprobleme", 7Z, 63, 2008, 529 ss.

Zimmermann, R., The Law of Obligations, Oxford, 1996. 